\title{
Positive Emotions' Role on Social Media Addiction among Chinese Young Adults
}

\author{
Xinlei Wang ${ }^{1, *}$ \\ ${ }^{1}$ University of California, San Diego, Rady School of Management, La Jolla, 92037, US \\ *Corresponding author's e-mail: Xinlei.Wang@rady.ucsd.edu
}

\begin{abstract}
With people spending more time on social media, addiction has become a social problem and has drawn much attention. Especially for young adults, social media has become an essential part of their life. This study examined the role of positive emotion played on social media addiction. The participants of this study included 250 young adults in China aged from 18-22 years old. The valid data was 203 participants, 102 female (50.2\%) and 101male (49.8\%). The data was collected using a questionnaire and were distributed by the Star online survey. The results of multiple regression analysis showed that the variances of influence on the overuse of social media from the most to the least were satisfaction, proud and sense of belonging, and the degree of influence on social media addiction is the sense of belonging, proud and satisfaction. Therefore, more attention could be paid to certain positive emotions when trying to prevent social media addiction in young Chinese adults.
\end{abstract}

Keywords: Positive emotions, social media addiction, overuse of social media

\section{INTRODUCTION}

With technologies getting more and more advanced, people found themselves cannot live without them. Especially during the Covid-19 pandemic, people spend much more time on social media since they cannot go out to meet with their friends, and this seems to be the only way to contact their friends and see the outside world. According to the statistic found by Brian Dean on the Backlinco blog, 3.96 billion people are using social media worldwide, and there is a $92.976 \%$ of increase from 2015 to 2021 [1]. With such a rapid increase in social media usage, the overuse of social media addiction has long become a concern even before the pandemic. Although the boundary between overuse of social media and social media addiction is still fuzzy, scientists are still debating whether overuse of social media is an addiction [2]. According to Webserv [3], social media addiction is the compulsive use of social media that intervenes in people's daily life. The possible negative effects of social media addiction include cyberbullying, sleep deprivation, pornography and sexting, and so on [4] with signs of mood modification (changes in mood state); Salience (Intense preoccupation); Tolerance (an increase of time using social media), withdrawal symptoms (anxiety if cannot get access of social media); conflict (interpersonal problems); relapse (return to excessive use after abstinence and so on [5].

The number of cases of social media addiction has been growing. According to [6], more than 200 million people likely suffer from social media addiction. What makes young adults get so addicted to those platforms? The relationship between emotions and addictive behavior has long been studied. Emotions are psychological states that are based on biological organisms and bound by circumstances. A study found that suffering from emotional dysregulation may lead to more addictive behavior [7]. Macklem [8] pointed out that addictions were related to the low ability of efficient emotion regulation. Yildiz [9] found that dysfunctional emotion regulation predicted smartphone addiction and Internet addiction. In the context of social media addiction, emotions like fear of missing out, loneliness, high level of stress, depression were all commonly recognized predictors of social media addiction. According to Blackwell et al. [10], fear of missing out was the major predictor of social media addiction. Also, Baltaci [11] pointed out that social media addiction was positively related to social anxiety and loneliness. Banyai and his colleagues [12] conducted a study that identified a positive relationship between depression and social media addiction. 
However, most previous studies mainly discussed the relationship between negative emotions and social media addiction. There is little research examined the role of positive emotions in social media addiction. Baltaci [11] mentioned that there was a negative relationship between happiness and social media addiction. Due to the lack of related research about positive emotions and social media addiction, this study would fill this gap.

Positive emotions, which are different from effect or feeling, are pleasant or desirable responses [13], the boundary of positive emotions is not well identified, but commonly recognized positive emotions include Gratitude, Pride, Happiness, Hope, Love, Satisfaction, and so on [14][15]. Therefore, this study chose to measure these commonly agreed on positive emotion elements: Proudness, Sense of Belonging (as a reflection of love from family and friends and satisfaction. This study investigated two stages separately: the first stage was the overuse of social media but not to the extent of addiction; the second stage, social media addiction, was considered.

The question of this research was: Do positive emotions have an impact on social media addiction? By exploring the relationship between positive emotions and social media addiction, the causes of social media addiction could be better understood. Meanwhile, effective treatments or prevention strategies could be developed to deal with social media addiction.

\section{METHOD}

\subsection{Participants and Procedure}

This cross-sectional study focused on Chinese young adults aged 18-25 years. The survey was distributed through Star online survey tool. To obtain a more sample, data were collected from respondents over one week. The initial sample contains 250 young adults in China. Forty-seven invalid questionnaires that do not meet the age criteria and have a short answer time (less than 3 minutes) were excluded. The valid data was 203 participants, 102 female (50.2\%) and 101male (49.8\%).

Positive emotion elements proudness was measured with a review of the satisfaction with life scale [16]. This scale consisted of five items, and participants rated their level of agreement on a 5-point Likert scale from 1 (very disagree) to 5 (very agree). A sample item of the scale was "I am confident in myself." $(\alpha=0.926)$. Sense of Belongingness was measured with General Belongingness Scale (GBS) [17]. GBS consisted of six items, and participants rated their level of agreement on a 5-point Likert scale from 1 (very disagree) to 5 (very agree). A sample item was "I have a feeling of belonging." ( $\alpha=0.860)$. Satisfaction was measured with Satisfaction with Life Circle (SWLC) (This scale consisted of five items, and participants rated their level of agreement on a 5-point Likert scale from 1 (very disagree) to 5 (very agree). A sample item of the scale was "My life is roughly in line with my ideal." $(\alpha=0.871)$.

Overuse of social media was measured with the development and psychometric characteristics of the Chinese Internet Addiction Scale [18]. This scale consisted of four items, and participants rated their level of agreement on a 5-point Likert scale from 1 (ver disagree) to 5 (very agree). A sample item of the scale was "I find myself spending more and more time on social media." $(\alpha=0.855)$.

Social media addiction was measured with the social media addiction scale [19]. This scale consisted of four items, and participants rated their level of agreement on a 5-point Likert scale from 1 (very disagree) to 5 (very agree). A sample item was "I have a strong dependence on social media." ( $\alpha=0.884)$.

These scales all have good validity, which can be found in articles like The Satisfaction With Life Scale and the emerging construct of life satisfaction [20]; The General Belongingness Scale (GBS): Assessing achieved belongingness [17], The Satisfaction With Life Scale and the emerging construct of life satisfaction( Pavot, Diener 2008), Development of Chinese Internet Addiction Scale and its psychometric study [18]; Revision and application of College Students' network dependence measurement tool [19].

\section{DATA ANALYSIS}

In this study, SPSS is used to do the descriptive statistics. Correlation analysis, Reliability test, Regression analysis and Validity test are also applied and tested.

\section{RESULTS}

\subsection{Descriptive statistics and Correlation analysis}

In this study, $30.5 \%$ of participants use social media for about 15-30 minutes, and 28.6\% use 30-60 minutes a day. And $39.9 \%$ of these young adults have 100-200 friends on social media.

The results of escriptive statistics and Correlation analysis were shown in Table 1. Correlation analysis is a statistical method to study the close relationship between variables. It mainly reflects whether there is a correlation between two kinds of variables or two phenomena in the direction and size of development and change, but it cannot reflect a causal relationship between the two kinds of phenomena. According to the statistical results, the correlation coefficients between overuse of social media and satisfaction, sense of being and reputation are 0.456 , 0.339 and 0.334 respectively, and the significance is 0.000 , less than 0.05 , indicating that overuse of social 
media has a significant positive correlation with satisfaction, sense of being and reputation. The correlation coefficients between social media addiction and satisfaction, sense of being and reputation were $0.289,0.325$ and 0.268 , respectively, and the significance was 0.000 , less than 0.05 , indicating a significant positive correlation between social media addiction and satisfaction of being and reputation.

Table 1 Means, standard deviations, and correlations coefficients of the main variables

\begin{tabular}{|c|c|c|c|c|c|c|c|c|c|}
\hline & $\mathrm{M}$ & SD & 1 & 2 & 3 & 4 & 5 & 6 & 7 \\
\hline 1 Gender & 1.50 & 0.50 & - & & & & & & \\
\hline 2 Education & 3.89 & 0.65 & 0.01 & - & & & & & \\
\hline 3 Satisfaction & 3.42 & 1.23 & 0.02 & $-0.21^{\star \star}$ & - & & & & \\
\hline 4 Sense of belongingness & 3.59 & 1.01 & $-0.15^{\star}$ & $-0.18^{*}$ & $0.39^{* *}$ & - & & & \\
\hline 5 Proudness & 3.48 & 1.13 & -0.02 & $-0.14^{\star}$ & $0.30^{* *}$ & $0.28^{* *}$ & - & & \\
\hline 6 Overuse of social media & 3.44 & 0.98 & -0.06 & $-0.15^{\star}$ & $0.46^{\star *}$ & $0.34^{\star *}$ & $0.33^{\star \star}$ & - & \\
\hline 7 Social media addiction & 3.33 & 1.27 & -0.10 & -0.14 & $0.29^{\star *}$ & $0.33^{\star *}$ & $0.27^{\star \star}$ & $0.31^{\star *}$ & \\
\hline
\end{tabular}

Notes. ${ }^{*} p<0.05,{ }^{* *} p<0.01$.

\subsection{Regression analysis}

In order to study the influence of positive emotions on the usage of social media, in this study, overuse of social media and social media addiction were used as dependent variables to conduct linear regression.

\subsubsection{Regression model 1}

In order to investigate the effect of satisfaction, sense of belonging and proudness on the overuse of social media, this study takes satisfaction, sense of belonging and proudness as independent variables and overuse of social media as dependent variables to construct a regression equation model. The results are shown in the following table:

Table 2 Results of regression analyses on the overuse of social media

\begin{tabular}{lll}
\hline & $\mathrm{M} 1$ & $\mathrm{M} 2$ \\
\hline Gender & -0.06 & -0.04 \\
Education & -0.15 & -0.02 \\
Satisfaction & & $0.34^{* *}$ \\
Sense of & & $0.14^{*}$ \\
belonging & & $0.19^{* *}$ \\
Proudness & & 203 \\
$\mathrm{~N}$ & 203 & 0.27 \\
$\mathrm{R}^{2}$ & 0.02 & 0.25 \\
Adj.R ${ }^{2}$ & 0.02 & $\mathrm{~F}(5,197)=14.73$ \\
$\mathrm{~F}$ & $\mathrm{~F}(2,200)=2.51$, & $p=0.000$ \\
$\Delta \mathrm{R}^{2}$ & $p=0.08$ & 0.248 \\
\hline
\end{tabular}

Table 2 shows the index of the fitting test of the model. The coefficient of determination $R^{2}$ is 0.286 , and the adjusted coefficient of determination $R^{2}$ is 0.264 , which indicates that the explanatory ability of the independent variable(satisfaction, sense of belonging and proudness )on the dependent variable(overuse of social media) And the explanatory ability of the independent variable(satisfaction, sense of belonging and proudness )on the dependent variable(overuse of social media) reaches 26.4\% $(F(5197)=14.728, p<0.001)$. Therefore, the regression model has a level of significance, which means the regression equation model has statistical and explanatory significance.

According to the regression coefficient, the VIG value of each variable is less than 5, so there is no multicollinearity problem. Satisfaction has a significant positive impact on overuse of social media $(\beta=0.340, p$ $<0.001)$. Sense of being has a significant positive impact on the overuse of social media $(\beta=0.142, p<0.001$. And proudness has a significant positive impact on the overuse of social media $(\beta=0.188, p<0.001)$. According to the regression coefficient, we can know that the influence on social media overuse is satisfaction, pride, and sense of belongingness.

\subsubsection{Regression model 2}

In order to study the impact of satisfaction, sense of belonging and proneness on social media addiction, this paper constructs regression equation model 2 with satisfaction, sense of belonging and proudness as independent variables and social media addiction as dependent variables. The results are shown in Table 3 .

Table 3 Results of regression analyses on the overuse of social media addiction

\begin{tabular}{lll}
\hline & $\mathrm{M} 3$ & $\mathrm{M} 4$ \\
\hline Gender & -0.10 & -0.07 \\
Education & -0.14 & -0.05 \\
Satisfaction & & $0.16^{*}$ \\
Sense of & & $0.20^{* *}$ \\
belonging & & $0.16^{*}$ \\
Proudness & & 203 \\
$\mathrm{~N}$ & 203 & 0.17 \\
$\mathrm{R}^{2}$ & 0.03 & 0.15 \\
Adj. ${ }^{2}$ & 0.02 & $\mathrm{~F}$ \\
$\mathrm{~F}$ & $\mathrm{~F}$ & $(5,197)=7.83, p$ \\
& $(2,200)=3.04, p$ & $=0.000$ \\
$\Delta \mathrm{R}^{2}$ & $=0.050$ & 0.16 \\
\hline
\end{tabular}


The judgment coefficient $R^{2}$ was 0.166 , and the adjusted judgment coefficient $R^{2}$ is 0.145 , which indicates the explanatory ability of the independent variable (satisfaction, sense of belonging and proudness) on the dependent variable (social media addiction), the explanatory ability of the independent variable (satisfaction, sense of belonging and proudness) on the dependent variable (social media addiction) reaches $14.5 \%(F(5197)=7.828, p<0.001)$. Therefore, the regression was significant, indicating that the regression has statistical and explanatory significance.

According to the regression coefficient, the VIF value of each variable is less than 5, so there is no multicollinearity problem. The satisfaction has a significant positive impact on social media addiction $(\beta$ $=0.155, p<0.001)$. The sense of belongingness has a significant positive impact on social media addition $(\beta=$ $0.200, p<0.001)$. And proudness has a significant positive impact on social media addition $(\beta=0.157, p<$ $0.001)$. According to the regression coefficients, we know that the degree of influence on social media addition is: Sense of belongingness, Proudness and Satisfaction.

\section{DISCUSSION}

According to our studies, we can know that the variances of influence on the overuse of social media are satisfaction, proudness and a sense of belongingness. The degree of influence on social media addiction is a sense of belongingness, proudness and satisfaction. It shows there is indeed a difference between overuse of social media and social media addiction, and the trigger might be the degree difference between satisfaction and a sense of belongingness. It indicates that certain positive emotions could be manipulated to treat overuse of social media or prevent the problem of social media addiction. From this study, we can see that the positive emotion element Sense of belongingness has a similar effect on the overuse of social media and Social media addiction; what difference is the influence of positive emotion element: Satisfaction and Proudness. The increase in the degree of satisfaction is correlated to the addition of social media. We could control the degree of Satisfaction hound adults feel with social media to prevent or mitigate the problem of social media addiction.

\section{CONCLUSION}

Positive emotions indeed play a role in the overuse of social media. As the literature review mentioned above, the definition of positive emotions is still fuzzy, and which exact positive emotion has a strong relationship with social media overuse and social media addiction could be further studied. Whether there is a culture difference could also be explored.
In addition, the study was conducted at a time when people were experiencing pandemics. Whether the behavior and emotions involved when using social media will differ when life goes back to normal is still in question.

\section{REFERENCES}

[1] Dean, B.D. (2021) Social Network Usage \& Growth Statistics: How Many People Use Social Media in 2021?. https://backlinko.com/social-media-users.

[2] Zendle, D., Bowden-Jones, H. (2019). Is excessive use of social media an addiction? BMJ, 365, 12171.

[3] Webserv. (2021) What Is Social Media Addiction?. https://webserv.io/what-is-social-media-addiction.

[4] American College of Obstetricians and Gynecologists. (2016). Concerns Regarding Social Media and Health Issues in Adolescents and Young Adults. https://www.acog.org/clinical/clinicalguidance/committee-

opinion/articles/2016/02/concerns-regarding-socialmedia-and-health-issues-in-adolescents-and-youngadults

[5] Glowiak, M.G. (2021) Social Media Addiction: Signs, Symptoms \& Treatments. Choosing Therapy. https://www.choosingtherapy.com/social-mediaaddiction.

[6] Mediakix. (2021). These 8 social media addiction statistics show where we're spending our time. https://mediakix.com/blog/social-media-addictionstatistics.

[7] Beauchaine, T.P., Crowell, S.E. (2020) The Oxford Handbook of Emotion Dysregulation (Oxford Library of Psychology). Oxford University Press, Oxford.

[8] Macklem, G.L. (2008) Practitioner's guide to emotion regulation in school-aged children. Springer, New York.

[9] Yildiz, M.A. (2017) Emotion regulation strategies as predictors of internet addiction and smartphone addiction in adolescents. J. Educ. Sci. Psychol., 7(1), 66-78.

[10] Blackwell, D., Leaman, C., Tramposch, R., Osborne, C., Liss, M. (2017) Extraversion, neuroticism, attachment style and fear of missing out as predictors of social media use and addiction. Pers. Indiv. Differ., 116, 69 - 72.

[11] Baltaci, N. (2019) The Predictive Relationships between the Social Media Addiction and Social Anxiety, Loneliness, and Happiness. Inter. J. Progr. Educ., 15(4), 73 - 82. 
[12] Bányai, F., Zsila, G., Király, O., Maraz, A., Elekes, Z., Griffiths, M.D., Andreassen, C.S., Demetrovics, Z. (2017) Problematic Social Media Use: Results from a Large-Scale Nationally Representative Adolescent Sample. PLOS ONE, 12(1), e0169839.

[13] Chon, M.A.C., Fredrickson, B.L.F. (2012) Positive Emotions. In: Snyder, C.R., Lopez, S.J.(Eds.), Oxford Handbook Online Scholarly Research Reviews. Oxford University Press, Oxford. pp. 1322.

[14] Carpenter, D.C. (2020) 10 Common Positive Emotions Beyond Happiness. https://www.verywellmind.com/the-nuances-ofhappiness-emotions-beyond-happiness-1717543.

[15] Ackerman, C.E. (2020) Positive Emotions: A List of 26 Examples \& Definition in Psychology. https://positivepsychology.com/positive-emotionslist-examples-definition-psychology.

[16] Pavot, W., Diener, E. (1993) Review of the Satisfaction with Life Scale. Psycholo. Assessment., 5(2), 164-172.

[17] Malone, G.P., Pillow, D.R., Osman, A. (2012) The General Belongingness Scale (GBS): Assessing achieved belongingness. Pers. Indiv. Differ., 52(3), 311-316.

[18] Chen, S.H., Weng, L.Z., Su,Y.R. (2003) Development and psychometric characteristics of Chinese Internet Addiction Scale. Chin. J. Psychol., 45(3), 279-294.

[19] Bai, Y., Fan, F.M. (2005) Revision and application of College Students' network dependence measurement tool. Psychol. Dev. Edu., 21(4), 99104.

[20] Pavot, W., Diener, E. (2008) The Satisfaction With Life Scale and the emerging construct of life satisfaction. J. Posit. Psychol., 3(2), 137 - 152. 